This item was submitted to Loughborough's Research Repository by the author.

Items in Figshare are protected by copyright, with all rights reserved, unless otherwise indicated.

\title{
Towards low carbon homes - a simulation analysis of building-integrated air- source heat pump systems
}

PLEASE CITE THE PUBLISHED VERSION

http://dx.doi.org/10.1016/j.enbuild.2012.01.019

PUBLISHER

(C) Elsevier

VERSION

AM (Accepted Manuscript)

LICENCE

CC BY-NC-ND 4.0

\section{REPOSITORY RECORD}

Rowley, Paul, and Loic Cabrol. 2019. "Towards Low Carbon Homes - a Simulation Analysis of Buildingintegrated Air-source Heat Pump Systems”. figshare. https://hdl.handle.net/2134/9539. 
This item was submitted to Loughborough's Institutional Repository (https://dspace.lboro.ac.uk/) by the author and is made available under the following Creative Commons Licence conditions.

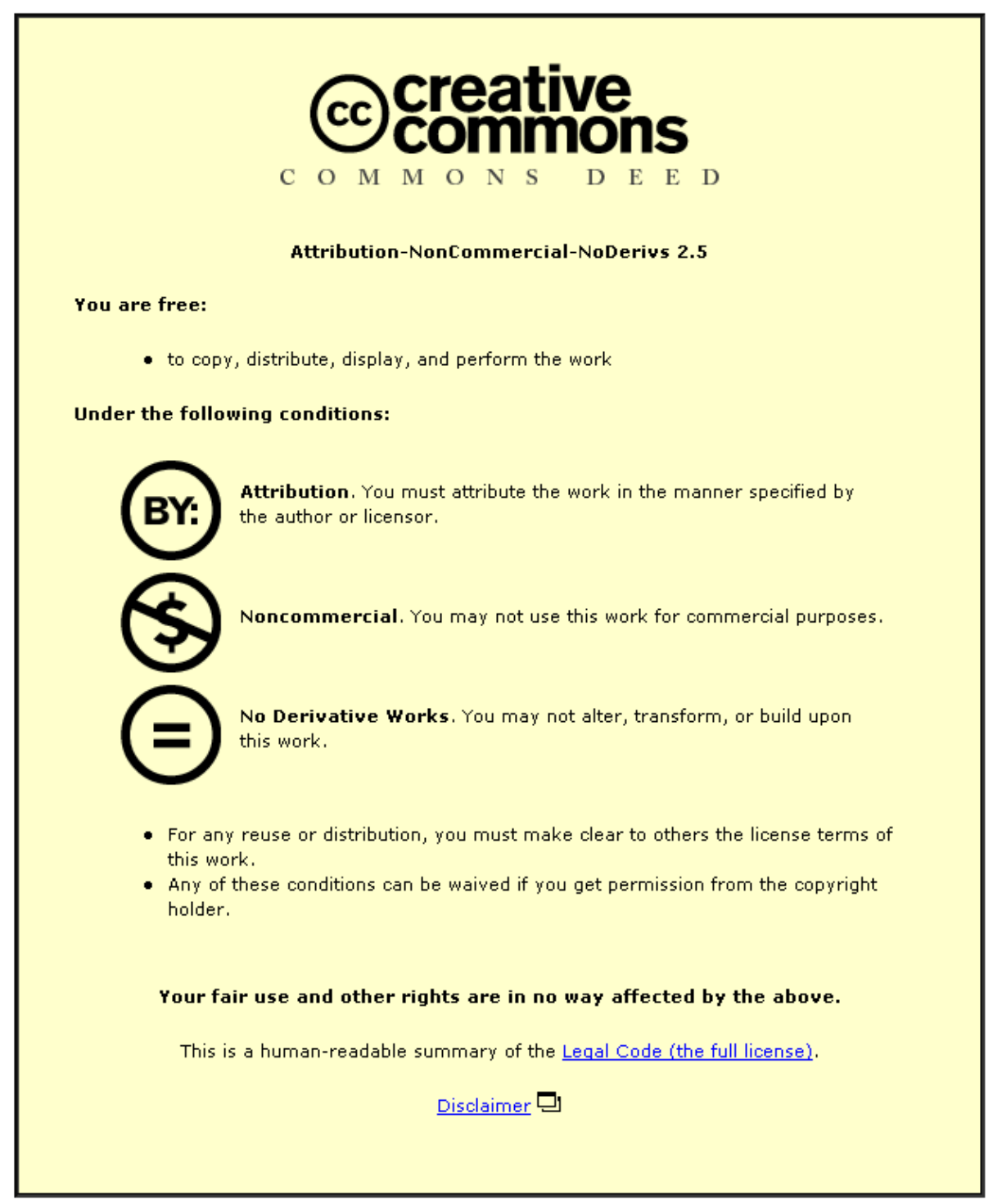

For the full text of this licence, please go to: http://creativecommons.org/licenses/by-nc-nd/2.5/ 


\title{
Towards Low Carbon Homes - A Simulation Analysis of Building-Integrated Air-Source Heat Pump Systems
}

\author{
Loïc Cabrol and Paul Rowley (corresponding author), \\ CREST (Centre for Renewable Energy Systems Technology), School of Electronic, Electrical \& Systems \\ Engineering, Loughborough University, Leics. LE11 3TU UK. \\ Email P.N.Rowley@1boro.ac.uk
}

\begin{abstract}
A comparative transient simulation analysis for domestic buildings with a floor-embedded heating system coupled to a modern air source heat-pump (ASHP) has been carried out using the TRNSYS numerical modeling environment for various UK locations. The effects of heat-pump control during off-peak electricity tariff periods in conjunction with varying building fabric characteristics were analysed and the results show that for the locations investigated, running costs and $\mathrm{CO}_{2}$ emissions were lower for the ASHP platform than for a comparative gas boiler heating system. It was also found that by utilizing the thermal mass of a concrete floor slab or by integrating external insulation, acceptable comfort levels during the heating season were maintained when operating the ASHP solely during off-peak tariff periods. A thinner concrete floor slab containing phase change material (PCM) provided a slightly improved comfort level during winter and also reduced overheating during summer in buildings with a high level of insulation. Finally, when utilising a floor-embedded PCM material, it was found that the thermal properties of the PCM material must be carefully matched with case-specific building fabric thermal performance parameters in order to ensure effective internal environmental control.
\end{abstract}

Keywords: Air source heat-pump, off-peak tariff, load shifting, PCM slab, floor heating, TRNSYS

\section{INTRODUCTION}

The EU faces significant challenges in meeting $\mathrm{CO}_{2}$ emission reduction targets of up to $80 \%$ by 2050 compared to 1990 levels. In the UK, domestic dwellings alone are currently responsible for nearly $30 \%$ of $\mathrm{CO}_{2}$ emissions. In addition to improved thermal performance of the building fabric, the integration of renewable energy technologies is seen as a key part of the solution required to significantly reduce domestic-sector carbon emissions [1]. With the additional goal to 'de-carbonise' the UK's electricity supplies in the medium term, electrically powered building heating solutions (replacing gas, oil or solid fuel powered technologies) are seen as a core strand of the UK's carbon emissions reduction strategy [2]. Within this context, heat pumps are projected to play a major role in domestic-sector heating provision, with air source heat pumps (ASHP) seen as a particularly attractive option owing to their relatively low cost in comparison with ground-coupled alternatives. Recent research has explored the carbon saving potential of groundcoupled heat pumps, and identified possible barriers to such savings, especially with regards the domestic retrofit sector [3]. Subsequent research [4] evaluated air source heat pump performance within a UK retrofit context, and suggested that carbon emission reduction of up to $12 \%$ were feasible compared to a gas boiler system, but with a projected $10 \%$ increase in running costs, depending on specific application parameters. Therefore, within such a distributed power generation and distribution framework, the option to employ a degree of demand management by shifting loads from peak to off-peak periods offers an advantage with regards reduced need for extra generation capacity and an increased utilisation of generating plant and hence increased efficiency of generation investment [5].

Heat-pump operational efficiency is often expressed as its coefficient of performance (COP), namely

$$
C O P=\frac{\text { Pthermal }}{\text { Pcompressor }}
$$

Therefore, a $6 \mathrm{~kW}_{\text {th }}$ heat-pump with a COP of 3 will produce $6 \mathrm{~kW}$ of heat for every $2 \mathrm{~kW}$ of electrical power supplied to the compressor and is therefore approximately 3 times more energy efficient than a $6 \mathrm{~kW}$ electric direct heater.

For a given electrical power supplied to an ASHP's compressor $\left(P_{\text {compressor }}\right)$, the thermal power $\left(P_{\text {thermal }}\right)$ transferred to the heat distribution fluid is normally larger by a factor related to the temperature difference between the heat source and sink. Thus, the COP of an ASHP and its thermal output power decrease when the ambient air temperature decreases 
or when the heat distribution fluid temperature increases. Since air temperatures are generally lower than those of the ground during the heating season, seasonal COPs for ASHPs are in theory generally lower than for ground source heatpumps (GSHP) that extract heat from the ground with a more stable temperature [6]. However, ASHP systems are often more convenient and economical to fit, and provided their operational efficiency is optimised, their large market penetration potential means that ASHP technology presents an important route towards significant $\mathrm{CO}_{2}$ reductions [7]. Furthermore, recent field trial data indicates that the performance gap between air and ground source heat pumps in the UK is not as large as previously assumed [6]

Clearly, the ability to utilize a building's thermal mass in order to 'de-couple' the electrical input and thermal output of an ASHP offers an opportunity to shift electrical load to off-peak periods, thereby offering electricity system efficiency benefits [7]. Where electricity suppliers offer tariff options during which electricity is cheaper during off-peak periods, optimising a building's holistic design to facilitate ASHP operation predominantly during off-peak periods also gives this technology a further advantage in term of operating costs. The inclusion of carefully designed phase change materials within the building envelope further enhances these potential benefits [8]

To de-couple the ASHP electrical and thermal loads, emitted heat is stored in the thermal mass of the building or in dedicated storage tanks and transferred at a later time to the air inside the building or for water heating purposes [9]. The sensible heat stored in a material is proportional to its thermal capacity, its temperature and its volume. Thus, to increase the sensible energy stored in a material, either (a) the heating distribution temperature; (b) the material volume or (c) the material's specific heat capacity need to be increased. The former option would not be preferred for an ASHP heating system, since higher outlet temperatures would lead to operation at a lower COP. In addition to increasing the available sensible heat capacity, a further potential option for energy storage is to use fabric-integrated phase change materials (PCMs). These have been investigated previously as a means to store both sensible heat and latent heat when they transition from one state to another (solid-liquid is the preferred transition for building applications). They also provide a stable temperature around their transition temperature when discharging heat leading to potentially improved internal comfort management [10].

The aim of this work is therefore to "assess how various control schemes based around off-peak electricity tariff options impact upon the technical and economic performance of an ASHP system for three different dwelling fabric construction methods".

Using the dynamic building simulation tool TRNSYS, the objectives of the work included:

- For each building configuration, to evaluate ASHP COPs and internal temperature variations for ASHP control based upon a number of currently available off-peak electricity tariff periods;

- To investigate performance for three different UK locations in order to evaluate climatic variations;

- To assess annual performance in terms of energy consumption, $\mathrm{CO}_{2}$ emissions and running costs for off-peak electricity tariffs, a flat-rate electricity tariff and a gas boiler respectively for each location and building type.

\section{METHODOLOGY}

For the purpose of this study, three contrasting dwelling fabric configurations were considered with integrated insulation layers primarily designed to provide various thermal mass and admittance/decrement properties, namely:

(a) Externally rendered lightweight structural insulated panel (SIP) wall and roof construction comprising plywood timber sheeting enclosing polystyrene insulation within a timber frame;

(b) Externally rendered insulated concrete formwork (ICF) wall and roof structure comprising a concrete core sandwiched between expanded polystyrene insulation layers and

(c) Traditional concrete blockwork structure with an externally rendered insulation layer.

The basic fabric parameters are described below in table 1. For each case, an exposed concrete floor slab was assumed, the thickness of which was varied and the impact upon internal temperature variations was evaluated. Additionally, the impact of a floor-embedded phase change material (PCM) upon the thermal response of the building was also evaluated. For each fabric configuration, two differing thermal insulation and infiltration scenarios which broadly reflect current and forthcoming UK building fabric legislation were analysed, namely: 
(d) A 'standard performance' building with U-values of $0.27 \mathrm{~W} / \mathrm{m}^{2} \mathrm{~K}$ for the walls, $0.27 \mathrm{~W} / \mathrm{m}^{2} \mathrm{~K}$ for the floor and $0.16 \mathrm{~W} / \mathrm{m}^{2} \mathrm{~K}$ for the roof. Windows had a $\mathrm{U}$-value of $1.4 \mathrm{~W} / \mathrm{m}^{2} \mathrm{~K}$ and a g-value of 0.59 . The infiltration rate was set to 0.5 air changes per hour $(\mathrm{ACH})$.

(e) A 'high performance' building with U-values of $0.13 \mathrm{~W} / \mathrm{m}^{2} \mathrm{~K}$ for the roof, the walls and the floor. Windows had a $\mathrm{U}$-value of $0.68 \mathrm{~W} / \mathrm{m}^{2} \mathrm{~K}$ and a g-value of 0.407 . The infiltration rate was set to $0.2 \mathrm{ACH}$.

\section{Table 1: Building design parameters for simulation purposes}

To investigate the suitability of ASHP technology for each building fabric scenario, ASHP control approaches based upon a number of standard and off-peak electricity tariffs were investigated, and the results compared in terms of daily internal temperature variations, seasonal ASHP efficiency (COPs), building electrical energy consumption, $\mathrm{CO}_{2}$ emissions and running costs. Table 2 presents the UK electricity tariffs investigated in the study. The most widely available are Economy 10 (E10) and Economy 7 (E7), which align quite closely with widely available variable rate tariff options across a number of EU countries in addition to the UK.

Table 2. 2009 UK electricity tariff options used in this study. An exchange rate of $€ 1=€ 1.16$ is used.

Finally, to assess the impacts of climactic variations on performance, evaluations were carried out for three differing UK locations, ranging from northern Scotland to southern England, as shown in Fig. 1.

Figure 1. UK ASHP performance simulation locations and annual $15.5^{\circ} \mathrm{C}$ heating degree days (HDD).

\subsection{TRNSYS Model Design Principle}

Among the numerous dynamic building simulation programs available, TRNSYS is one of the most widely used and has been extensively validated (including against BESTEST scenarios for example), thereby resulting in a good level of confidence in its outputs $[13,14]$. In order to test the impact of specific parameters independently of each other, a parameterised model was developed, in which the selection of either real or custom meteorological conditions (such as temperature, solar radiation or humidity) is possible. Similarly, specific control strategies, electricity tariff options and occupancy patterns were selected and evaluated. To better understand the interactions coming into play in the system and to simplify the investigation of control effects, only single zone buildings were defined, and thermal bridging was not considered for simplification.

\subsection{Air Source Heat Pump model}

The investigated ASHP model was an 'Ecodan' designed by Mitsubishi Electric. It can generate up to $9 \mathrm{~kW}$ of thermal power for a water flow of $0.44 \mathrm{~L} / \mathrm{s}$ and is designed to run with water output temperatures ranging from $35^{\circ} \mathrm{C}$ to $55^{\circ} \mathrm{C}$. Its compressor is inverter driven, and thus its output can be continuously adjusted to generate from 50 to $100 \%$ of the maximum output power as required. Such capacity-controlled ASHP systems with weather compensation have the potential for better performance than heat pumps with on/off control [15]. Data from tests performed by an independent laboratory [16] were used as the basis for the ASHP model. Manufacturer's data was used only to define the maximum output power as a function of the ambient temperature.

As ASHP systems extract heat from the ambient air, frost can build up and accumulate on the evaporator leading to a loss of efficiency. To counter this effect, ASHP units periodically initiate defrost cycles typically for 2 to 5 minutes duration. Where defrosting is facilitated by reverse-cycling, this can reduce overall ASHP performance. Defrost cycles have been modelled previously [17] as a COP reduction $\left(C O P_{\text {reddefrost }}\right)$ defined by a modified gaussian curve derived via the application of a biquadratic polynomial approximation. It was shown that for ambient temperatures $\left(T_{a m b}\right)$ below $7^{\circ} \mathrm{C}$, the defrost parameter can be defined as:

$$
\text { COPreddefrost }=-0.0027 *(\text { Tamb }-7)+0.1801 \cdot \mathrm{e}^{-\frac{T_{a m b}^{2}}{5}}
$$

For $T_{a m b}$ above $7^{\circ} \mathrm{C}$, the defrost parameter was defined as:

$$
\text { COPreddefrost }=0.1801 \cdot \mathrm{e}^{-\frac{T_{a m b}^{2}}{5}}
$$

For the unit under consideration in this study, the ASHP maximum thermal output power $\left(P_{\max }\right)$ is $9 \mathrm{~kW}$ for an ambient temperature of $7^{\circ} \mathrm{C}$ or more. Below this temperature, the output can be defined as: 


$$
P \max =9 \cdot\left(-0.00081 \cdot T_{a m b}^{2}+0.01083 \cdot T_{a m b}+0.9593\right)
$$

Using biquadratic polynomial curve fitting derived from operational data [16,17], the COP at maximum power $\left(C O P_{P \max }\right)$ was defined as a function of the water temperature exiting the $\operatorname{ASHP}\left(T_{\text {outlet }}\right)$ and the ambient temperature $\left(T_{a m b}\right)$ :

$$
\begin{aligned}
& C O P P \max =5.292237+0.000187 \cdot T_{\text {outlet }}^{2}+0.000425 T_{\text {amb }}^{2} \\
& -0.002657 \cdot T_{\text {outlet }} \cdot T_{\text {amb }}-0.072435 \cdot T_{\text {outlet }}+0.194939 T_{\text {amb }}
\end{aligned}
$$

During periods when the heat pump does not operate at full capacity, its performance varies. The mean part load ratio (PLR) corresponds to the energy supplied by the heat pump during a simulation time step divided by the maximum energy it would supply if working at full capacity. The mean part load factor (PLF) is the correction applied to the COP at full capacity as a function of the PLR.

Long term observations performed on real inverter-driven heat-pumps suggest that the PLF varies as $(c$ PLR $+d)$ under heat- capacity controlled conditions, then as PLR/ $(a$ PLR $+b)$ under on and off conditions at low PLR [19]. Parameters $c$ and $d$ were computed using PLF $=1.17$ for a PLR of 0.5. Although real data was available for the Ecodan showing periodic cycles, it gave no clear evidence of the COP reduction at low PLR. Thus, for simulation purposes $a$ and $b$ parameters were calculated assuming that for a PLF of $1, \operatorname{PLR}=0.2$, and $a=0.754 ; b=0.049 ; c=-0.346 ; d=1.346$, thus:

$$
\mathrm{PLF}=\mathrm{PLR} /(0.754 \mathrm{PLR}+0.049)
$$

Whilst for a PLR of 0.5 to 1 :

$$
\text { PLF }=-0.346(\text { PLR + 1.346) }
$$

\subsection{Heat Distribution System}

An under-floor heating system is implemented in the current study due to the relatively low heat distribution water temperatures required to maintain internal temperatures, which is favourable to the efficiency of the ASHP operation. Moreover, the exposed concrete floor slab's relatively high thermal mass and more optimal admittance and decrement factors can be used to aid effective thermal load shifting.

In TRNSYS, a floor heating system was defined using thermally active layers that were configured as arrays of parallel tubes filled with water inserted between two layers of identical materials. The water flow and temperature at the tube inlet was controlled externally by the model. Rather than using a finite element model requiring a lot of computational power, a simplified TRNSYS model was utilized for the active layer. This aids computational time, but puts some constraints on the minimum water flow. The water temperature is assumed to be uniform in the tube, which is effectively true if the water flow rate is above a specific limit. Since the minimum water flow required in our system was much lower than this limit, active layer segmentation was required in which the building floor area was divided into 11 smaller areas of equal sizes connected in series. In each of these smaller sections, the approximation of a uniform temperature could be made with little error. However, because of this simplified approach, switching the water flow on then off could lead to some power lost in the active layer. To rectify the problem, when turning off the heating system, the water flow in the active layer was kept on with the water temperature at the inlet equal to the outlet temperature.

\subsection{Effects of Floor Slab-Integrated Phase Change Materials}

Previous work carried out by Farid et al [12] found that a concrete slab mixed with an encapsulated $\mathrm{CaCl}_{2}-6 \mathrm{H}_{2} \mathrm{O} P C M$ of latent heat of fusion of $196 \mathrm{~kJ} / \mathrm{kg}$, a mass fraction of 0.12 and a melting temperature of $28^{\circ} \mathrm{C}$ exhibited a more stable temperature response compared to a uniform concrete slab of the same thickness. In the present study, the effect of a similar floor configuration as a means of aiding the maintenance of optimal indoor comfort levels outside the off-peak electrical tariff periods was examined via the development and implementation of a model of this type of slab. No PCM type is defined in the standard TRNSYS library. However, an active layer can be used as a simple approach to simulate a PCM material. Since a phase change material can be considered as a material having a variable thermal capacity, the capacity of the fluid in the active layer can be changed according to the energy extracted or absorbed by the fluid flowing in the active layer [20]. However, as this method sometimes results in computational convergence problems around phase transitions, a slightly different method was used in which the fluid of the active layer was considered to be water circulating at high flow, with an approximately uniform temperature in the tube. The energy removed by the fluid from the active layer during each simulation step was integrated to represent the energy stored in the PCM material. The 
temperature of the PCM was then deduced based on its effective thermal capacity. At each subsequent time-step, the water at the inlet of the active layer was set to the new PCM temperature.

To simulate a floor heating system with a concrete slab including a PCM, one slab representing the heating layer was defined, along with an additional layer representing the PCM. A direct contact between the two slabs was simulated by using a coupling zone of negligible volume and by defining very high convective coefficients. In the present study, the effects of candidate PCMs of different melting temperature ranges were considered. To make the simulation results transferable to other PCMs than $\mathrm{CaCl}_{2}-6 \mathrm{H}_{2} \mathrm{O}$, the effects of a PCM layer with a lower latent heat of fusion were also analysed.

\subsection{System Control}

To assess the building's dynamic response under discontinuous off-peak control conditions independently of relatively complex weather interactions, an initial simulation was performed where the external temperature and solar radiation were set to $0^{\circ} \mathrm{C}$ and $0 \mathrm{~W} / \mathrm{m}^{2}$ respectively. A proportional-integral-derivative (PID) controller then adjusted the power injected into the floor heating system to maintain an internal temperature of $20^{\circ} \mathrm{C}$ over a period of $360 \mathrm{~h}$. This initial period was required in order to attain a stable temperature inside the building and derive the average thermal power $\left(P_{\text {avg }}\right)$ required to maintain the $20^{\circ} \mathrm{C}$ set point within the building. After this, power was pulsed during off-peak periods to maintain an average temperature of $20^{\circ} \mathrm{C}$, during which period the power delivered $P_{\text {applied }}=P_{\text {avg }} \times 24 /$ (total off peak hours).

To assess the building's yearly performance, a second simulation was carried out which included location-specific climate and weather conditions along with the availability and nature of specific tariffs. In this case, the controller attempted to compensate the theoretical thermal energy deficit of the building during off-peak periods. If at the end of a specific off-peak period an energy deficit remained, on peak operation was enabled but only during the most favorable daytime hours in terms of COP.

The thermal energy deficit was estimated by integrating the following equation:

$$
P_{\text {deficit }}=P_{\text {avg }} / 20 \times \max \left(0,20-T_{a m b}\right)-0.7 \times \text { Occupational Heat Gain }
$$

Where $P_{\text {avg }}$ is the average thermal power found in the first simulation. To avoid a drift between the actual and the estimated energy deficit, the deficit was set to 0 if the internal temperature remained above $20^{\circ} \mathrm{C}$ during 24 hours.

\section{DATA ANALYSIS}

\subsection{Impact of Tariff Selection on ASHP and Building Performance}

Simulations were carried out for the three different UK locations as shown in Figure 1 in order to assess both climatic effects and various control strategies upon ASHP performance. Firstly, for all locations, the impact of ASHP control aligned with various off-peak electricity tariffs was examined. To obtain an overview of the ASHP performance, the average $\mathrm{COP}$ at maximum capacity for each hour of the day weighted by the degree-day was calculated as follows and is represented in Fig. 2.

$$
C O P W e i g h t D e g D a y(h)=\frac{\sum_{\mathrm{d}=1}^{365} \operatorname{COP}(h, d) \cdot \text { DegreeDay }(d)}{\text { DegreeDays }}
$$

In equation (6), $C O P(h, d)$ represents the ASHP COP at maximum capacity for the hour of the day $h$ and for day $d$, DegreeDay $(d)$ is the degree day for day $d$. DegreeDays is the number of degree days for a complete year assuming a base temperature of $15.5^{\circ} \mathrm{C}$.

Fig. 2 shows that as expected the average ASHP COP is higher in the relatively mild climates of the UK Midlands and South (locations A and B) than in the cooler Northern climate of Aviemore, in this case by 7.7\%. However, the results show that although the daytime ASHP performance is clearly higher in the southern location of Bracknell compared to the more northern Sutton-Bonington $(+3.6 \%$ at $14 \mathrm{~h})$, their performances are very similar during the night (from 0 to $7 \mathrm{~h}$ ). Therefore, the use of an Economy 7 night-time only tariff in the Bracknell area would not result in the potential efficiency advantages resulting from the milder day-time conditions. Furthermore, if a night-time room temperature set-back control strategy is adopted for Bracknell in order to improve ASHP night-time efficiencies, then a space 
heating energy deficit may accrue for the subsequent day due to the lower energy input during the 7 hour off-peak period.

\section{Figure 2. Average coefficient of performance weighted by degree-day for Bracknell (A), Sutton-Bonington (B) and Aviemore (C).}

For each off-peak tariff, Figure 3 summarizes ASHP performance during the 7 off-peak hours for which the highest COPs were obtained. Economy 10, Option14 and TwinHeat B tariffs have very similar performances. The use of the TwinHeat A tariff leads to a lower average COP because the night-time off-peak portion coincides with the coldest period (3am-7am). Similarly, Economy 7 is the least efficient tariff option for all locations because the single off-peak period (midnight-7am) corresponds to the time during which the ASHP has the lowest COPs due to low ambient temperatures. This leads to approximately a $10 \%$ average COP decrease compared to Economy 10, which has three off peak periods, including two daytime periods. It should be noted that the adoption of the aforementioned night-time setback control strategy would help improve ASHP operational efficiencies, but with the potential drawback of reducing the total amount of stored energy available from the floor slab and other thermal mass elements for subsequent use during peak tariff periods. Option 14 and Economy 10 tariffs also have the advantage of offering more than 7 hours of off-peak time, which helps to reduce the constraint on ASHP configuration and control. For example, if ASHP operation occurs solely during off-peak periods, the required building heating energy load for one complete day must be delivered in off-peak time. Therefore, for the Economy 7 tariff, the ASHP's rated output will need to be larger than that of a heat pump that is designed to run on-demand at any time of the day. Finally, having several off-peak periods is beneficial in limiting temperature swings during the day.

\section{Figure 3. Comparison for several electricity tariffs of the estimated yearly average ASHP COP for Bracknell (BR), Aviemore (AV) and Sutton Bonington (SB).}

\subsection{Impact of Building Envelope Characteristics}

For the cases of 'high performance' dwellings, Fig. 4 shows the effect of floor slab concrete thickness on internal temperature variation for an ASHP on/off duty cycle of 6 hours. In this case, the simulation assumes a constant outside temperature and the various wall and roof structures as indicated.

It can be seen that for an insulated concrete formwork (ICF) wall and roof structure, increasing the floor slab thickness has the consequence of (a) delaying the maximum temperature peaks compared to the turning off and on of the heating, and (b) reducing the peak-to-peak amplitude. Therefore, a thicker floor slab acts to facilitate a more stable internal temperature when the ASHP is switched off for long periods. In this case, the slab's thermal inertia acts like a low pass filter to delay the thermal response of the system, and a thicker slab effectively decreases the low-pass filter cut-off frequency.

As a rule of thumb for the ICF structure, the delay introduced by the slab is shown to be approximately 1 hour for the first $100 \mathrm{~mm}$ of concrete above the pipes and one additional hour for each further $50 \mathrm{~mm}$ of concrete. The ICF structure time lags are very similar as those indicated for the lightweight structural timber insulated panel (SIP) configuration, whilst the time lag for externally insulated walls is shown to be shorter as seen in Fig. 4. For the ICF structure, this behaviour is the result of isolating the concrete wall and roof thermal mass due to the presence of an internal EPS insulation layer, with these configurations effectively offering low admittance values between the inside air and the wall. In contrast, the externally insulated wall has its high thermal mass element in direct contact with the internal air mass, presents a high admittance value, and so rapidly absorbs heat transferred from the slab to the air, thus reducing the time lag and also further reducing the amplitude of the temperature variation. The results also show that higher wall U-values resulted in a negligible shift in temperature lag, but larger temperature swings due to the increased building heating load. Similarly, higher infiltration/ventilation rates do not affect the load shift but do increase the temperature swings. It should be noted that the floor slab thicknesses suggested here are not atypical for the UK, where combined slab plus screed depths can range from 100-300mm depending on specific circumstances. Furthermore, the results of this study suggest that the preferred location of any underfloor sheet insulation should be beneath high thermal mass elements in order to optimize internal thermal management. Currently, this is not typically the case, with insulation commonly located above the main slab and beneath the surface screed. 
Figure 4. Effect of slab thickness $(100 \mathrm{~mm}$ or $250 \mathrm{~mm})$ on the internal temperature swings in pulsed heating mode for various wall and roof configurations $(\mathrm{EI}=$ external insulation, $\mathrm{IC}=$ insulated concrete formwork, $\mathrm{SIP}=$ structural insulated panel).

\subsection{Effects of Slab-integrated Phase Change Material}

Fig. 5A the shows the effects on internal temperature of embedded PCMs of varying melting temperatures, and for a constant external temperature of $0^{\circ} \mathrm{C}$. For a relatively low PCM melting temperature of $23^{\circ} \mathrm{C}$ (denoted as $22 / 24 \mathrm{PCM}$ in Fig. 5) the material's latent energy is utilised in its transition phase only at the end of the long ASHP-off period as the slab temperature decreases towards the transition temperature range. However, for a $\mathrm{PCM}$ with a melting point of $25^{\circ} \mathrm{C}$ (denoted 24/26PCM), the PCM is always in its transition phase region, and acts to smooth the room temperature fluctuations $\left(1.5^{\circ} \mathrm{C}\right.$ peak-to-peak versus $1.9^{\circ} \mathrm{C}$ for the $\left.22 / 24 \mathrm{PCM}\right)$. For a $195 \mathrm{~mm}$ concrete slab, the indoor air temperature exhibits a smaller peak-to-peak fluctuation of $1.2^{\circ} \mathrm{C}$, with an increased temperature lag in relation to the ASHP's power pulses. Conversely, for the notional building with externally insulated concrete walls, the 24/26PCM slab reduces the temperature lag because of the effectively closer coupling between the concrete's thermal mass and the PCM at a lower temperature.

Fig. 5B shows that for an ambient temperature of $10^{\circ} \mathrm{C}$, the $24 / 26 \mathrm{PCM}$ always stays in solid phase, while the $22 / 24 \mathrm{PCM}$ is always in its transition phase due to the lower water temperature in the floor-integrated heating distribution system. The impact of the $22 / 24 \mathrm{PCM}$ slab on room temperature stabilization is significant $\left(0.4^{\circ} \mathrm{C}\right.$ peak-topeak versus $0.7^{\circ} \mathrm{C}$ for the $0.195 \mathrm{~mm}$ concrete slab and $1.2^{\circ} \mathrm{C}$ for the $24 / 26 \mathrm{PCM}$ slab).

Figure 5. Fluctuations of PCM temperature and inside air temperature for the 'standard performance' ICF building with different slab configurations when heat is pulsed (pon) for an external temperature of $0^{\circ} \mathrm{C}$ (a) and $10^{\circ} \mathrm{C}(\mathbf{b})$.

For the 'high performance' buildings, Fig. 6 shows the effects of using a concrete slab mixed with a $21.5 / 23.5^{\circ} \mathrm{C}$ melting range PCM during the summer and winter seasons respectively. Fig. 6A shows that the benefit imparted by the $\mathrm{PCM}$ is pronounced during summer when the maximum internal temperature is reduced by approximately $1^{\circ} \mathrm{C}$. Benefits in winter are also apparent, with minimum internal air temperatures arising from the PCM slab increased by approximately $0.75^{\circ} \mathrm{C}$.

Figure 6. Room temperature fluctuations of the 'high performance' building with ICF walls and roof for a $195 \mathrm{~mm}$ concrete slab with and without a $21.5 / 23.5^{\circ} \mathrm{C}$ melting range PCM during (A) summer and (B) winter when heated during Economy 10 tariff off-peak periods.

\subsection{Performance Summary}

Tables 3 to 5 show performance summaries for ASHP and a gas boiler within an ICF 'standard' and 'high performance' building configuration.

Table 3 shows that for a 'standard performance' building in Sutton Bonington, a maximum simulated yearly ASHP COP close to 4 is attained for Economy 10 (E10) tariff control and decreases to a COP of 3.5 for Economy 7 tariff (E7) control. This is the equivalent to an increase of around $15 \%$ in the annual energy requirement; however, it should be noted that this deficit could be reduced via the use of a night-time set-back control strategy whilst being mindful of the need to maintain a stored energy provision for subsequent peak-time heating. The impact of tariff-based control is similar in Aviemore, but with a lower average annual COP arising from overall lower ambient temperatures. For the 'high performance' building (which requires an ASHP rated output around half that of that for the 'standard' building) comparable COP results are evident. As would be expected, for this more thermally efficient building envelope, energy consumption is on average more than $50 \%$ lower than that for the 'standard' building.

Table 3. Yearly ASHP performance summary for both a 'standard' and a 'high performance' building for two electricity tariff options (E7 or E10) in Sutton Bonington (SB) and Aviemore (AV).

A simulated electricity cost comparison for the E10 and flat rate tariffs respectively is shown in Table 4. This indicates that E10 cost savings for heat pump operation are particularly pronounced for the 'Standard performance' building, especially in the colder climate of Aviemore. E10 tariff heat pump running cost savings are less pronounced for the high performance building; indeed, flat rate tariff heat pump running costs are slightly lower than E10 in the milder climate of Sutton Bonington. However, when appliance and parasitic energy costs are accounted for in addition to those for the ASHP, significant savings accruing from E10 operation are apparent in all cases. 
Table 4. Yearly running costs for E10 and flat rate tariffs for both a 'standard' and a 'high performance' building in Sutton Bonington (SB) and Aviemore (AV).

Table 5 shows a comparison of ASHP E10 tariff performance compared with an equivalent gas boiler solution. In all cases, the ASHP solution has a lower indicated running cost compared to the gas boiler, although it should be noted that cost reductions would not be as significant for a flat rate tariff ASHP control option (table 3). In terms of $\mathrm{CO}_{2}$ emissions, the simulations show that a reduction of as much as $36 \%$ is attainable for the high performance building.

Table 5. Yearly E10 tariff ASHP and gas boiler performance summary for both a 'standard' and a 'high performance' ICF building in Sutton Bonington (SB) and Aviemore (AV).

\subsection{Comfort versus Occupancy}

Although a measure of comfort can be estimated in TRNSYS simulations using the Predicted Percentage Dissatisfied (PPD) output value, this parameter varies according to specific dwelling zones, activity levels and clothing factors. Temperature settings also differ for zones of differing occupancy such as bedrooms and living areas. In this study, the model consists of only one zone with a control set-point temperature of $20^{\circ} \mathrm{C}$. At times the temperature could fall marginally below this leading to a high PPD. Therefore, the comfort criteria used was to maintain a temperature above $19^{\circ} \mathrm{C}$ when the building was occupied.

Table 6 shows that for the 'standard performance' building, the slab with the 22/24PCM meets the comfort criteria for all the investigated cases, while the thick concrete slab meets the comfort criteria only in conjunction with externally insulated walls. For ICF construction, the 22/24PCM slab also acts to reduce the minimum and maximum temperature amplitude by $0.9^{\circ} \mathrm{C}$ when the building is occupied by a single person and by $1.3^{\circ} \mathrm{C}$ when occupied by a family of 4 . This effect is less noticeable for the externally insulated construction. As expected, Economy 7 tariff control leads to a degraded performance compared to economy 10.

Table 6. Minimum and maximum room temperatures for a baseline building in Sutton Bonington between the $6^{\text {th }}$ and $31^{\text {st }}$ of January depending on the electricity tariff, the building construction type (IC $=$ insulated concrete; $\mathbf{E I}=$ external insulation) and the floor slab configuration.

\section{DISCUSSION}

For those buildings investigated in this study with a relatively high thermal mass, internal temperature control proved to be challenging. For discontinuous off-peak tariff ASHP control, the approach taken in this study was firstly to assess the peak-time thermal power deficit while the ASHP was turned off arising from the requirement to maintain a specific internal temperature set-point. Then, during off-peak periods the ASHP control compensated by generating enough energy to keep the subsequent peak-time deficit equal to zero, within the time constraints of the off-peak tariff period. One refinement of this control strategy is to sample the power deficit at the end of a specific off-peak period. If this value is high, then the ASHP can be turned on during peak tariff times, but only at the most advantageous period of the day to get the best COP. Further improvements could be made via the implementation of various compensation patterns for the power deficit during off-peak periods in order to optimise the COP or the thermal comfort.

The simulation indicates significantly lower running costs for ASHP-based systems compared to an equivalent condensing gas boiler solution. This arises from the relatively high operational efficiency of the ASHP compared to a gas boiler equivalent, and the extensive use of low-cost off-peak tariffs for ASHP operation. It should be noted that simulated ASHP COPs in this study are greater than average compliance performance benchmarks used elsewhere [21]. This is largely due to the relatively low water distribution temperature in the floor slab required to maintain space heating loads, typically less than $30^{\circ} \mathrm{C}$ during ASHP operation. This results in the ASHP operating with a low temperature difference between the ambient air and the water outlet. Indeed, comparison of the simulation model results with real measurements made during water tank heating tests starting from $12^{\circ} \mathrm{C}[16$ ] showed that the model slightly underestimated the measured COPs. Conversely, one should be mindful of the results of recent UK field trial studies that indicate a significant variation in the performance of ASHP systems in real operational environments [6].

In this study, the model adopts variable speed control of the compressor in order to adjust the output power between the maximum and $50 \%$ of rated output as required. Lower output powers require the compressor to be periodically turned off. Another approach could be to control the water mass-flow in the heating circuit in order to reduce the ASHP output 
power. In any event, implementing the control based on power deficit compensation would most likely require some modifications of the ASHP controller.

As part of an integrated programme of research, work is ongoing to validate the results of this and other simulation studies via extensive and long term monitoring of a number of domestic and commercial/industrial buildings, the outcomes of which will be published in subsequent papers.

\section{CONCLUSIONS}

The results presented here are useful in suggesting design approaches for a building with a floor heating system coupled to an ASHP operated during off-peak periods, and suggest that such a strategy can be an attractive option in terms of both $\mathrm{CO}_{2}$ emissions and running costs. Specifically:

- The use of an off-peak tariff option helps optimise the balance between enabling acceptable operational efficiency whilst maintaining low running costs;

- For a 'standard performance' building, either a $20 \mathrm{~cm} / 2300 \mathrm{~kg} / \mathrm{m}^{3}$ concrete floor slab with externally insulated fabric construction or a $10 \mathrm{~cm}$ concrete slab embedding a PCM melting at $24^{\circ} \mathrm{C}$ with walls insulated internally or externally is optimal;

- For a 'high performance' building, a $20 \mathrm{~cm}$ concrete floor slab or a $10 \mathrm{~cm}$ concrete slab embedding a PCM melting at $22.5^{\circ} \mathrm{C}$ is recommended;

- The PCM floor slab improves temperature stability during the heating season and reduces the risk of overheating during summer for the high performance building;

- The ASHP yearly COP reached 4 for a mild climate and 3.5 for a colder climate with an economy 10 electricity option. With economy 7, the COP was reduced, which increased the electricity requirement by 11 to $15 \%$ if a nighttime set-back control option is not adopted;

- In all cases, reduced operating costs and $\mathrm{CO}_{2}$ emissions compared to a design with a condensing gas boiler are indicated;

- Increasing the thickness of the floor slab or the use of external insulation can reduce the temperature fluctuations, whilst compared to a thick concrete slab, a thin concrete slab mixed with an encapsulated PCM material melting at $22.5^{\circ} \mathrm{C}$ in a highly insulated building displayed a slightly improved temperature stability during the heating season, but also a greater stability during summer, reducing the risk of overheat.

\section{ACKNOWLEDGEMENTS}

The authors would like to thank Jordan Jeewood from Mitsubishi Electric UK for the numerous information regarding Ecodan heat-pump and Laurence Steijger from Silvercrest EC for his useful advice.

\section{REFERENCES}

[1] Department of Trade and Industry (2007) Meeting the Energy Challenge a White Paper on Energy, May 2007. [Online] Available from: http://www.berr.gov.uk/files/file39387.pdf [Accessed 12 February 2011].

[2] H. Singh, A. Muetze, P.C. Eames, Factors influencing the uptake of heat pump technology by the UK domestic sector, Renewable Energy 35 (4) 2010 873-878.

[3] D.P. Jenkins, R. Tucker and R. Rawlings, Modelling the carbon-saving performance of domestic ground-source heat pumps, Energy and Buildings 41 (6) 2009 587-595

[4] N.J. Kelly, J. Cockroft, Analysis of retrofit air source heat pump performance: Results from detailed simulations and comparison to field trial data, Energy and Buildings 43 (1) 2011 239-245.

[5] G. Strbac, Demand side management: Benefits and challenges, Energy Policy 36 (12) 2008 4419-4426.

[6] J.F. Urchueguía, M. Zacarés, J.M. Corberán, Á. Montero, J. Martos, H. Witte, Comparison between the energy performance of a ground coupled water to water heat pump system and an air to water heat pump system for heating and cooling in typical conditions of the European Mediterranean coast, Energy Conversion and Management 49 (10 2008 2917-2923.

[7] J. Cockroft, N.J. Kelly, A comparative assessment of future heat and power sources for the UK domestic sector, Energy Conversion and Management 47 (15-16) 2006 2349-2360.

[8] Getting warmer: a field trial of heat pumps. Energy Saving Trust, September 2010. [Online] Available from: http://www.energysavingtrust.org.uk/Media/node_1422/Getting-warmer-a-field-trial-of-heat-pumps-PDF [Accessed 11 February 2011] 
[9] T. Y. Chen. Real-time predictive supervisory operation of building thermal systems with thermal mass. Energy and Buildings 33 (2) 2001 141-150.

[10] A. Sharma, V.V. Tyagi, C.R. Chen, D. Buddhi, Review on thermal energy storage with phase change materials and applications, Renewable and Sustainable Energy Reviews 13 (2) 2009 318-345.

[11]F. Agyenim, N. Hewitt, The development of a finned phase change material (PCM) storage system to take advantage of off-peak electricity tariff for improvement in cost of heat pump operation. Energy and Buildings 42 (9) 2010 1552-1560.

[12] M Farid and W.J. Kong, Underfloor heating with latent heat storage, Proceedings of the Institution of Mechanical Engineers, Part A: Journal of Power and Energy 215 (5) 2001 601-609.

[13]D.B. Crawley, J.W. Hand, M. Kummert, B. T. Griffith, Contrasting the capabilities of building energy performance simulation programs, Building and Environment 43 (4) 2008 661-673.

[14] J. Neymark, R. Judkoff, G. Knabe, H.T. Le, M. Dürig, A. Glass, G. Zweifel, Applying the building energy simulation test (BESTEST) diagnostic method to verification of space conditioning equipment models used in wholebuilding energy simulation programs, Energy and Buildings 34 (9) 2002 917-931

[15]F. Karlsson, P. Fahlen, Capacity-controlled ground source heat-pumps in hydronic heating systems; International Journal of Refrigeration 30 (2) 2007 221-229.

[16] Building Research Establishment, Mitsubishi PUHZ-W90VHA air to water heat pump tests, 15 May 2007, Test

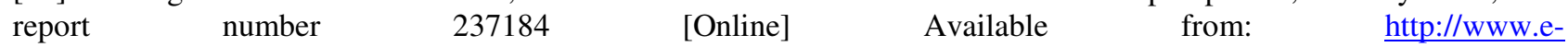
si.com/downloads/BRE\%20Test\%20Report\%20Mitsi_W90.pdf [Accessed 12 February 2011].

[17] T. Afjei, M. Wetter, Compressor heat pump including frost and cycle losses, Version 1.1: Model description and implementing into TRNSYS. June 23, 1997; Zentralschweizerisches Technikum Luzern [Online] Available from: http://www.transsolar.com/_software/download/en/ts_type_401_en.pdf [Accessed 22 January 2011].

[18] K. Gregory, B. Moghtaderi, H. Sugo, A. Page, Effect of thermal mass on the thermal performance of various Australian residential constructions systems, Energy and Buildings 40 (4) 2008 459-465

[19] E. Bettanini, A. Gastaldello, L. Schibuola, Simplified models to simulate part load performances of air conditioning equipments, Proc. IBPSA $8^{\text {th }}$ Int. Conf. Building Simulation '03, Eindhoven, Netherlands, 2003, 107-114.

[20] Manuel Ibañez, Ana Lazaro, Belen Zalba ,Luisa F.Cabeza, An approach to the simulation of PCMs in building applications using TRNSYS, Applied Thermal Engineering 25 (11-12) 2005 1796-1807.

[21] SAP 2005: The Government's Standard Assessment Procedure for Energy Rating of Dwellings. Published on behalf of DEFRA by BRE, Garston, Watford, WD25 9XX UK. [Online] Available from: http://projects.bre.co.uk/sap2005/pdf/SAP2005.pdf [Accessed 14th February 2011]. 


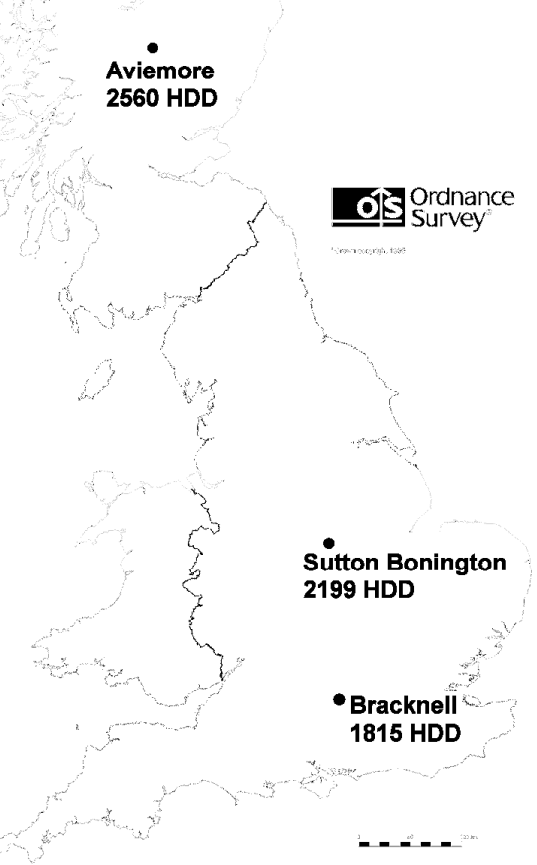

Figure 1. UK ASHP performance simulation locations and annual $15.5^{\circ} \mathrm{C}$ heating degree days (HDD).

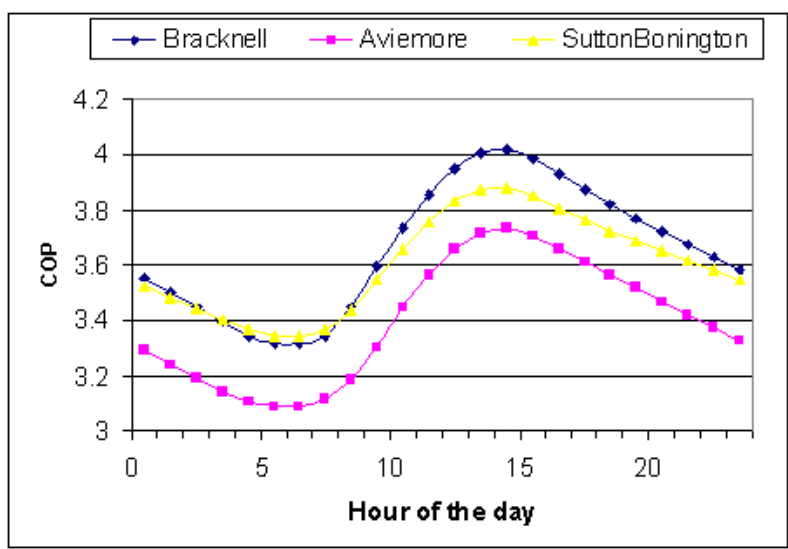

Figure 2. Average coefficient of performance weighted by degree-day for Bracknell (A), Sutton-Bonington (B) and Aviemore (C).

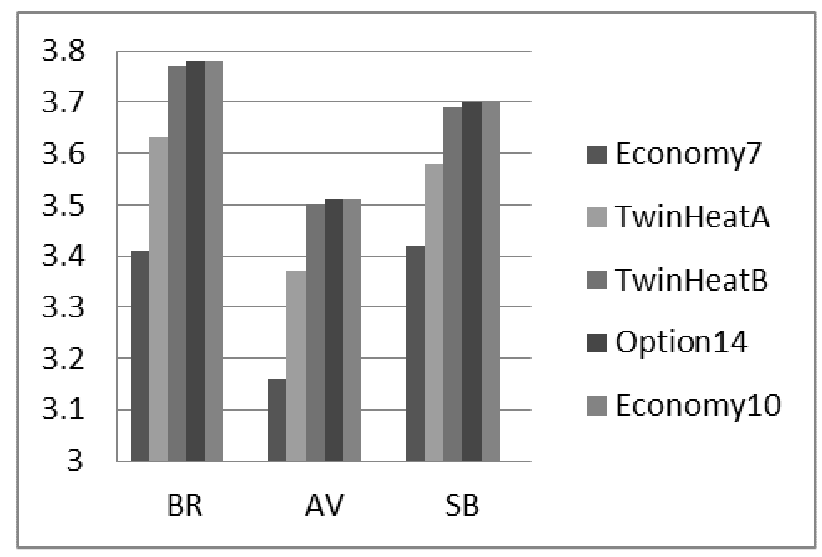


Figure 3. Comparison for several electricity tariffs of the estimated yearly average ASHP COP for Bracknell (BR), Aviemore (AV) and Sutton Bonington (SB).

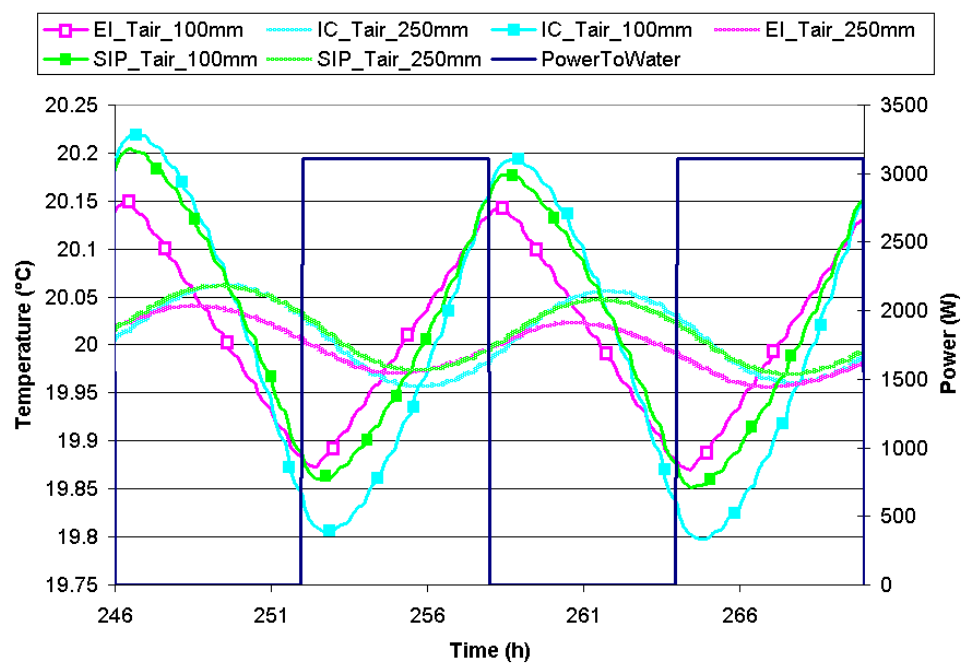

Figure 4. Effect of slab thickness $(100 \mathrm{~mm}$ or $250 \mathrm{~mm}$ ) on the internal temperature swings in pulsed heating mode for various wall and roof configurations $(\mathrm{EI}=$ external insulation, $\mathrm{IC}=$ insulated concrete formwork, SIP = structural insulated panel).
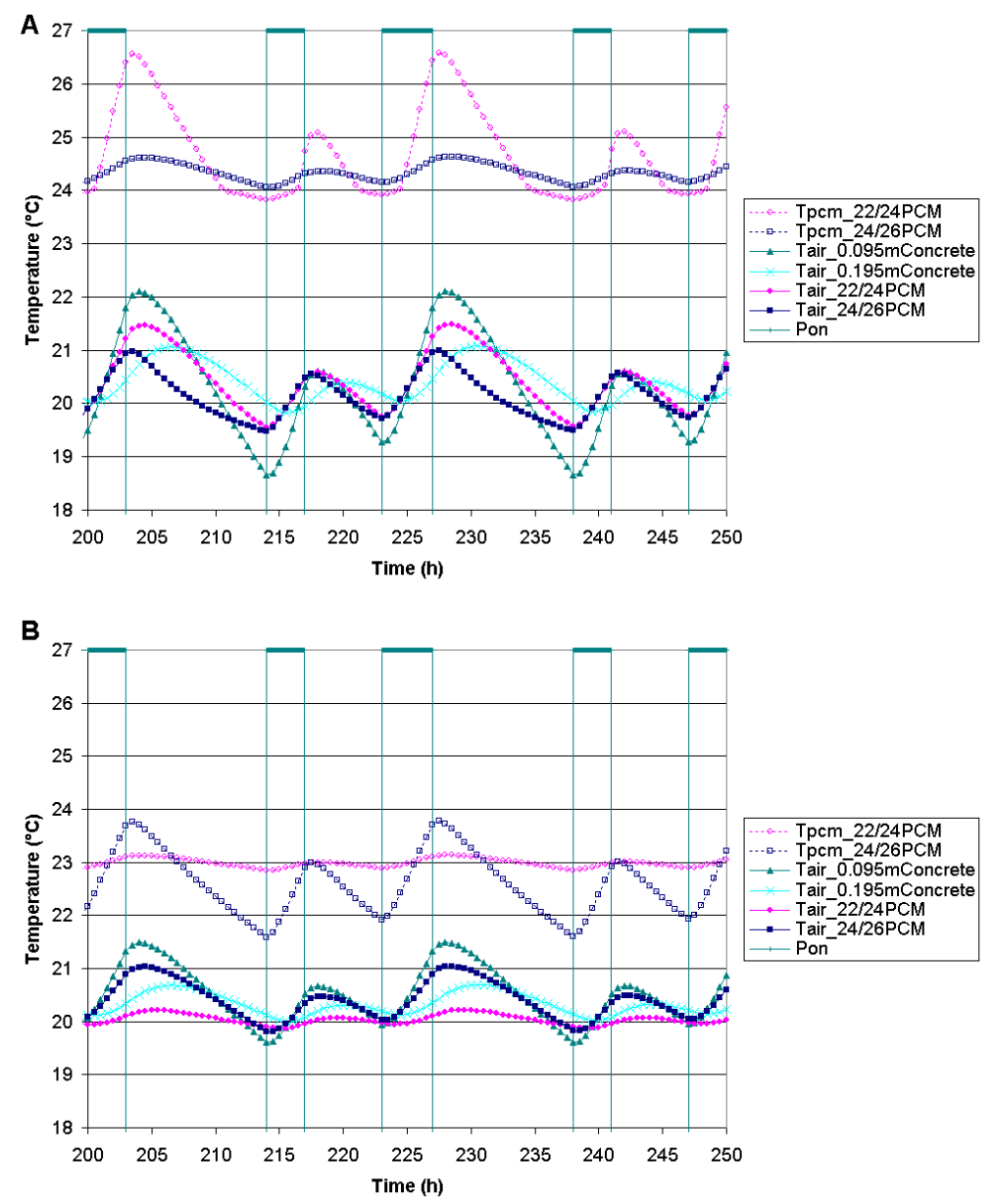

Figure 5. Fluctuations of PCM temperature and inside air temperature for the 'standard performance' ICF building with different slab configurations when heat is pulsed (pon) for an external temperature of $0^{\circ} \mathrm{c}$ (a) and $10^{\circ} \mathrm{c}(\mathrm{b}$ ). 

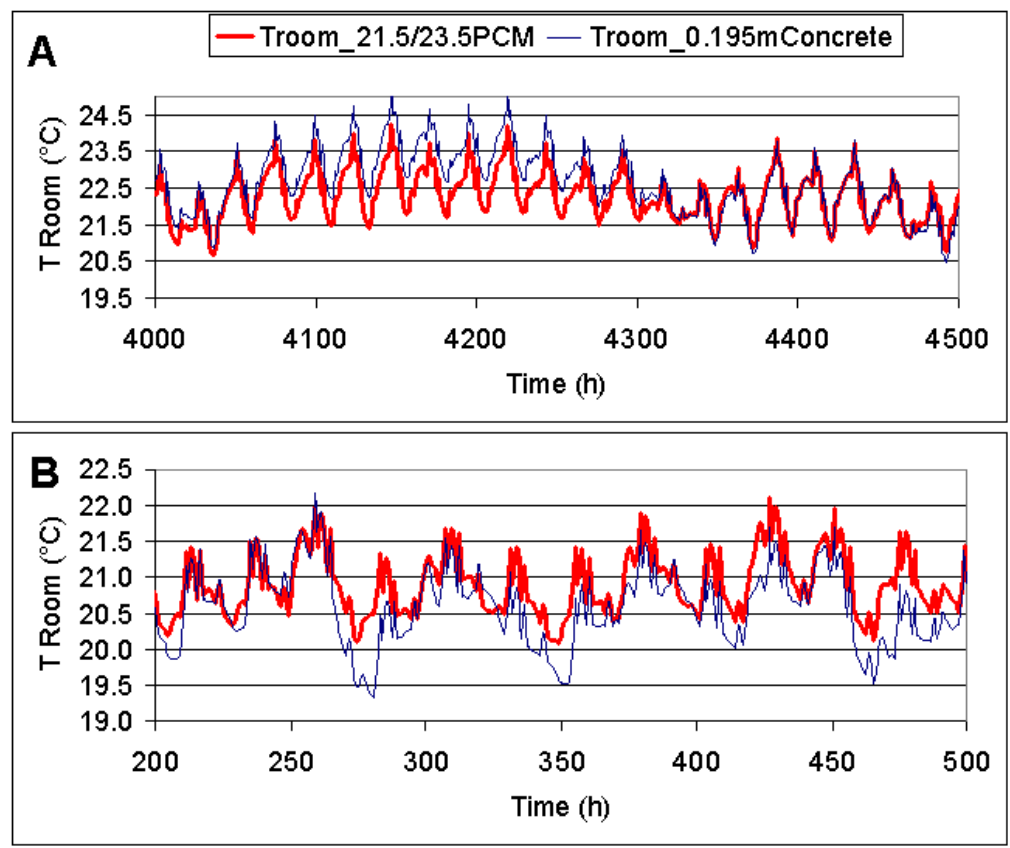

Figure 6. Room temperature fluctuations of the 'high performance' building with ICF walls and roof for a 195mm concrete slab with and without a $21.5 / 23.5^{\circ} \mathrm{C}$ melting range PCM during (A) summer and (B) winter when heated during Economy 10 tariff off-peak periods.

\begin{tabular}{|c|l|l|}
\hline Height $(\mathrm{m})$ & 2.4 & \\
\hline Width $(\mathrm{m})$ & 12 & $\mathrm{~N} \& S$ \\
\hline Depth $(\mathrm{m})$ & 10 & $\mathrm{E} \& \mathrm{~W}$ \\
\hline Window areas $\left(\mathrm{m}^{2}\right)$ & 3.00 & $\mathrm{~N}$ \\
\hline & 6.00 & $\mathrm{~S}$ \\
\hline & 3.75 & $\mathrm{E}$ \\
\hline & 3.75 & $\mathrm{~W}$ \\
\hline & 3.06 & Internal walls \\
\hline Convection coefficients $\left(\mathrm{W} / \mathrm{m}^{2} \mathrm{~K}\right)$ & 17.8 & External walls \\
\hline & 277 & Floor-to- ground \\
\hline & 9 & \\
\hline Transfer function time base (hours) & 0.5 & \\
\hline Wall and roof heat capacity $(\mathrm{kWh} / \mathrm{K})$ & 2.99 & SIP \\
\hline & 14.50 & ICF \\
\hline & 14.20 & Externally insulated \\
\hline
\end{tabular}

Table 1: Building design parameters for simulation purposes

\begin{tabular}{|l|l|c|c|c|}
\hline Tariff & $\begin{array}{l}\text { Off-peak time } \\
\text { (hours) }\end{array}$ & $\begin{array}{l}\text { Daily } \\
\text { service } \\
\text { charge }(€)\end{array}$ & $\begin{array}{l}\text { Peak kWh } \\
\text { (€) }\end{array}$ & $\begin{array}{l}\text { Off-peak } \\
\text { kWh (€) }\end{array}$ \\
\hline Economy 7 & 0 to 7 & 0.206 & 0.148 & 0.059 \\
\hline TwinHeatA & $\begin{array}{l}3 \text { to } 7, \\
13.5 \text { to } 16.5\end{array}$ & 0.206 & 0.148 & 0.067 \\
\hline TwinHeatB & $\begin{array}{l}12 \text { to } 15, \\
21 \text { to } 1\end{array}$ & 0.206 & 0.148 & 0.067 \\
\hline Option14 & $\begin{array}{l}21 \text { to } 8, \\
13 \text { to } 16\end{array}$ & 0.231 & 0.174 & 0.066 \\
\hline Economy10 & $\begin{array}{l}0 \text { to } 5, \\
13 \text { to } 16, \\
20 \text { to } 22\end{array}$ & 0.275 & 0.138 & 0.071 \\
\hline $\begin{array}{l}\text { Standard } \\
\text { tariff }\end{array}$ & $24 \mathrm{~h}$ & 0.149 & 0.136 & - \\
\hline
\end{tabular}


Table 2. 2009 UK electricity tariff options used in this study

\begin{tabular}{|c|c|c|c|c|c|c|c|c|}
\hline \multirow{2}{*}{\begin{tabular}{|l} 
Building Type \\
Location \\
\end{tabular}} & \multicolumn{4}{|c|}{ Standard } & \multicolumn{4}{|c|}{ High } \\
\hline & SB & SB & $\mathrm{AV}$ & $\mathrm{AV}$ & SB & SB & AV & $\mathrm{AV}$ \\
\hline Electricity Tariff & E10 & E7 & E10 & E7 & E10 & E7 & E10 & E7 \\
\hline \begin{tabular}{|lr} 
Heat & Pump \\
electrical & energy \\
$(\mathrm{kWh})$ & \\
\end{tabular} & 2756 & 3014 & 4078 & 4536 & 1246 & 1387 & 1895 & 2112 \\
\hline \begin{tabular}{|l} 
Heat $\quad$ Pump \\
running cost (€)
\end{tabular} & 297 & 266 & 400 & 385 & 191 & 163 & 243 & 220 \\
\hline Yearly COP & 4.02 & 3.50 & 3.52 & 3.10 & 4.09 & 3.67 & 3.66 & 3.28 \\
\hline \begin{tabular}{|lr} 
Appliance & + \\
Parasitic & energy \\
$(\mathrm{kWh})$ & \\
\end{tabular} & 3180 & 3132 & 3196 & 3158 & 2447 & 2434 & 2461 & 2448 \\
\hline $\begin{array}{l}\text { Appliance } \\
\text { Parasitic running } \\
\text { cost }(€)\end{array}$ & 334 & 376 & 335 & 378 & 258 & 295 & 259 & 296 \\
\hline \begin{tabular}{|ll}
$\begin{array}{l}\text { Total } \\
(\mathrm{kWh})\end{array}$ & electricity \\
\end{tabular} & 5936 & 6146 & 7273 & 7694 & 3694 & 3821 & 4356 & 4560 \\
\hline \begin{tabular}{|l} 
Total electricity \\
cost $(€)$
\end{tabular} & 632 & 642 & 737 & 765 & 449 & 458 & 502 & 516 \\
\hline
\end{tabular}

Table 3. Yearly ASHP performance summary for both a 'standard' and a 'high performance' building for two electricity tariff options (E7 or E10) in Sutton Bonington (SB) and Aviemore (AV).

\begin{tabular}{|c|c|c|c|c|}
\hline Building Type & \multicolumn{2}{|c|}{ Standard } & \multicolumn{2}{c|}{ High } \\
\hline Location & SB & AV & SB & AV \\
\hline Heat Pump running cost (E10) (€) & 297 & 400 & 191 & 243 \\
\hline Heat Pump running cost (Flat rate) $(€)$ & 383 & 566 & 174 & 263 \\
\hline Lighting, appliance \& parasitic cost (E10) (€) & 334 & 335 & 258 & 259 \\
\hline $\begin{array}{c}\text { Lighting, appliance \& parasitic cost (Flat rate) } \\
(€)\end{array}$ & 442 & 444 & 340 & 341 \\
\hline E10 saving & 192 & 274 & 64 & 103 \\
\hline
\end{tabular}

Table 4. Yearly running costs for E10 and flat rate tariffs for both a 'standard' and a 'high performance' building in Sutton Bonington (SB) and Aviemore (AV).

\begin{tabular}{|l|c|c|c|c|}
\hline Building Type & \multicolumn{2}{|c|}{ Standard } & \multicolumn{2}{c|}{ High } \\
\hline Location & SB & AV & SB & AV \\
\hline E10 Heat Pump running cost (€) & 297 & 400 & 191 & 243 \\
\hline Equivalent gas running cost (€) & 595 & 739 & 330 & 411 \\
\hline Heat Pump CO2 emissions (kg) & 1480 & 2190 & 669 & 1018 \\
\hline Equivalent gas CO2 emissions (kg) & 2284 & 2953 & 1050 & 1427 \\
\hline $\begin{array}{l}\text { Heat pump solution cost reduction } \\
(€)\end{array}$ & 297 & 339 & 139 & 168 \\
\hline $\begin{array}{l}\text { Heat pump solution } \mathrm{CO}_{2} \text { reduction } \\
(\%)\end{array}$ & $-35 \%$ & $-26 \%$ & $-36 \%$ & $-29 \%$ \\
\hline
\end{tabular}

Table 5. Yearly E10 tariff ASHP and gas boiler performance summary for both a 'standard' and a 'high performance' ICF building in Sutton Bonington (SB) and Aviemore (AV).

\begin{tabular}{|l|c|c|l|l|l|}
\hline Occupancy & Tariff & Insulation & Slab & $\begin{array}{l}\text { Tmin } \\
\left({ }^{\circ} \mathrm{C}\right)\end{array}$ & $\begin{array}{l}\text { Tmax } \\
\left({ }^{\circ} \mathrm{C}\right)\end{array}$ \\
\hline $\begin{array}{l}\text { Family of 4 } \\
7 \mathrm{~h}-8 \mathrm{~h} 30,\end{array}$ & E10 & ICF & 22/24PCM & 19.52 & 22.19 \\
\cline { 2 - 6 } & E10 & EI & $22 / 24 \mathrm{PCM}$ & 19.27 & 22.23 \\
\hline
\end{tabular}




\begin{tabular}{|l|c|c|l|l|l|}
\hline $17 \mathrm{~h} 30-23 \mathrm{~h}$ & E10 & ICF & $\begin{array}{l}0.195 \mathrm{~m} \\
\text { concrete }\end{array}$ & 18.83 & 22.81 \\
\cline { 2 - 6 } & E10 & EI & $\begin{array}{l}0.195 \mathrm{~m} \\
\text { concrete }\end{array}$ & 19.28 & 22.40 \\
\hline $\begin{array}{l}\text { Single person } \\
7 \mathrm{~h}-22 \mathrm{~h}\end{array}$ & E10 & ICF & $22 / 24 \mathrm{PCM}$ & 19.08 & 23.09 \\
\cline { 2 - 6 } & E10 & EI & $22 / 24 \mathrm{PCM}$ & 19.02 & 22.00 \\
\cline { 2 - 6 } & E10 & ICF & $\begin{array}{l}0.195 \mathrm{~m} \\
\text { concrete }\end{array}$ & 18.85 & 23.78 \\
\cline { 2 - 6 } & E10 & EI & $\begin{array}{l}0.195 \mathrm{~m} \\
\text { concrete }\end{array}$ & 19.18 & 22.44 \\
\cline { 2 - 6 } & E7 & EI & $\begin{array}{l}\text { 0.195m } \\
\text { concrete }\end{array}$ & 18.75 & 22.66 \\
\hline
\end{tabular}

Table 6. Minimum and maximum room temperatures for a baseline building in Sutton Bonington between the $6^{\text {th }}$ and $31^{\text {st }}$ of January depending on the electricity tariff, the building construction type (ICF = insulated concrete; EI = external insulation) and the floor slab configuration. 